\title{
Future physician-scientists: could we catch them young? Factors influencing intrinsic and extrinsic motivation for research among first-year medical students
}

\author{
Belinda W. C. Ommering $~ \cdot$ Floris M. van Blankenstein ${ }^{1,2}$ • Cathelijn J. F. Waaijer ${ }^{1}$. Friedo W. Dekker ${ }^{1,3}$
}

Published online: 13 July 2018

(c) The Author(s) 2018

\begin{abstract}
Introduction The medical field is currently facing a physician-scientist shortage. One possible solution is to direct medical students towards a research oriented career. To do so, knowledge is needed on how to motivate medical students to do research. Therefore, this study examines motivation for research and identifies factors influencing intrinsic and extrinsic motivation for research among first-year medical students.

Methods First-year medical students were surveyed at the beginning of their bachelor's program in 2016. On a 7-point Likert scale, students reported their motivation for research, self-efficacy, perceptions of research, curiosity, and need for challenge. Regression analyses were used to examine the influence of these factors on students' motivation for research. Results Out of 316 approached students, 315 participated (99.7\%). On average, students scored 5.49 on intrinsic, and 5.66 on extrinsic motivation for research. All factors measured influenced intrinsic and extrinsic motivation for research significantly and positively, also after adjusting for gender and age. Cumulative regression showed that these factors explained $39.6 \%$ of the variance in intrinsic, and $14 \%$ in extrinsic motivation for research.

Discussion All factors play an important role in intrinsic and, to a lesser extent, extrinsic motivation for research. First-year medical students' motivation for research could be enhanced by stimulating positive self-efficacy beliefs, positive perceptions of research, and curiosity. Also, it is important to fulfil students' needs for challenge by stimulating them to actively conduct research. Thus, to catch students young and cultivate physician-scientists, students should be stimulated to engage in research from the beginning of medical training.
\end{abstract}

Keywords Undergraduate research $\cdot$ Motivation $\cdot$ Physician-scientists $\cdot$ Medical education

\section{What this paper adds}

This paper builds on existing literature that advocates engaging medical students in research to counteract the decline of physician-scientists. Studies focusing on motivating medical students for research are scarce, and mainly con-

This paper received The Netherlands Association for Medical Education Best Research Paper Award 2017.

Belinda W. C. Ommering

b.w.c.ommering@lumc.nl

1 Center for Innovation in Medical Education, Leiden University Medical Center, Leiden, The Netherlands

2 Department of Higher Education, Leiden University Graduate School of Teaching, Leiden, The Netherlands

3 Department of Clinical Epidemiology, Leiden University Medical Center, Leiden, The Netherlands centrate on clinical phases. Moreover, those studies often lack a sound theoretical framework. We used Self-Determination Theory to investigate motivation for research among first-year medical students. Our findings show that first-year medical students are already motivated for research and that their motivation is influenced by self-efficacy, perceptions of research, curiosity, and need for challenge. This offers possibilities to 'catch students young' and stimulate early engagement in research to cultivate physician-scientists.

\section{Introduction}

According to the Canadian Medical Education Directives for Specialists (CanMEDS), all doctors should be able to critically appraise and use research in clinical practice to form decisions and make a grounded diagnosis [1]. Furthermore, it is necessary for doctors to keep up with cur- 
rent developments within their field of expertise [2]. To use research and apply evidence-based practice doctors should be able to understand research [3-6].

Not only should all physicians use research, there is also a need for doctors to conduct research. Research can contribute to the creation of new knowledge, which is necessary to keep doctors up-to-date and to make progress in the dynamic world of medical healthcare [4, 5, 7]. Physicianscientists can bridge the gap between science and practice, by translating research outcomes into clinical settings [8-11]. Moreover, physician-scientists encounter actual relevant clinical questions and problems, which can serve as inspiration for scientific research [12].

Currently, there is a shortage in the number of physicianscientists, as too few doctors pursue a scientific career [1, 8, 11, 13-15]. In a recent review, Chang and Ramnanan stated that in Europe, the United States, and Canada, interest in research among physicians is still decreasing [1]. Milewicz and her colleagues published a report in 2015 showing that too few young physicians pursue a scientific career, stressing the urgent need to direct more physicians towards research [16]. To summarize, the medical field is developing rapidly, and consensus exists on the urgent need for more physician-scientists. However, how future doctors can be stimulated to pursue a scientific career is still debated $[4,8,9,17-21]$.

Recent literature suggests that early engagement of medical students in research might be an effective solution [1-5, $11,21,22]$. This may not only help to trigger enthusiasm and stimulate future engagement in research [1, 23, 24], but may also help to recognize talent and to help this talent develop into physician-scientists [25].

To stimulate medical students for and keep them interested in research, it is important to know what motivates them for doing research in early phases of medical training and which factors contribute to their motivation for research. Most medical students in the Netherlands start their medical education after graduating from high school, at the age of 18-20 years. It is unknown if these young students recognize the importance of doing research, and in what way they are motivated to do research.

With regard to motivation in general, studies have shown that medical students are highly motivated, because of their large investment in entering medical school [26]. Less is known about their motivation specifically for research and studies relying on a sound theoretical framework are scarce. One study using Self-Determination Theory (SDT) indicated that students view research as valuable for their future medical career [3]. However, these results were mostly applicable to students in clinical years, and less to students in pre-clinical phases.

SDT distinguishes two main types of motivation: intrinsic and extrinsic motivation. Furthermore, SDT identifies three basic psychological needs influencing motivation: the need for competence, autonomy, and relatedness [26, 27]. In this study, we focus on the outcome measures of the SDT, namely intrinsic and extrinsic motivation. In the context of medical education, students can be extrinsically motivated to do research because it is beneficial for future training and career opportunities, for example to secure a competitive residency spot $[1,11,28-30]$. Additionally, there is evidence that students can be intrinsically motivated for research, and participate out of interest and enjoyment [11, 28, 29]. Students could also have both intrinsic and extrinsic motives for doing research [31].

We investigated four factors that may influence intrinsic and extrinsic motivation to conduct research at the start of medical training. The first factor, self-efficacy, is a person's belief in his or her own ability to accomplish a certain outcome [32]. Studies indicated that people are more inclined to follow a certain path if they are confident in their own capability in that domain, and that self-efficacy for research contributes to motivation for a research oriented career [32-34]. In this study, we explored students' beliefs in their general capabilities (i. e. general self-efficacy), academic capabilities (i.e. academic self-efficacy), and research-related capabilities (i. e. research self-efficacy). Previous studies suggested that higher levels of general and academic self-efficacy increase students' engagement in challenging tasks [35]. Doing research is considered to be a complex, and therefore challenging task, especially for first-year students. Therefore all three types of self-efficacy might play a role in influencing motivation for research.

The second factor we investigated was perceptions of research: students' beliefs about the value of research and learning. Perceptions of research as a predictor of motivation for research has not yet been investigated. However, a relation between these factors seems plausible. For instance, positive perceptions of research might co-occur with higher motivation for research. If so, it could be valuable to promote positive perceptions of research during medical training.

The third factor we investigated was curiosity: the desire to gain new knowledge. Berlyne introduced the concept of 'epistemic curiosity' and described this as 'the drive to know' (1954, P. 187) [36]. Epistemic curiosity can be divided into two types: interest curiosity concerns the satisfaction in discovering new ideas, and deprivation curiosity concerns the effort spent on finding solutions to a problem [37]. In medical education, students are stimulated to ask questions in order to enhance learning (i.e. interest curiosity) [6]. Additionally, students have to solve problems when they encounter difficulties and unknown areas (i.e. deprivation curiosity). Previous research showed that curiosity underlies motivation for and participation in research [22, $24,25]$. We investigated which type of curiosity was more 
important in affecting motivation for research. This could provide insights into which type of curiosity should be encouraged explicitly during medical training.

The fourth factor we investigated was need for challenge, specifically the need for extracurricular challenges. Some students need extra challenges, which, if not satisfied, could lead to drop out or lower academic performance [38]. If need for challenge influences motivation for research, educators can stimulate students by having them participate in research, for instance by offering challenging research projects.

To investigate if students are motivated to conduct research and which factors influence motivation, we posed the following research questions: 1) to what extent are first-year medical students intrinsically and/or extrinsically motivated for research; and 2) what influence do self-efficacy, perceptions of research, curiosity, and need for challenge have on intrinsic and extrinsic motivation for research among first-year medical students? If we know the nature of students' motivation for research and which factors influence motivation for research, evidence-based strategies can be implemented to enhance medical students' interest in research, and the first step to educate the next generation of physician-scientists can be made. Moreover, it could also have implications for the recruitment of students for medical training, as it could provide insights into how to attract possible future physician-scientists.

\section{Methods}

\section{Participants}

This study surveyed first-year medical students at Leiden University Medical Center. All students starting their medical education (bachelor's program) in 2016 were asked to participate in this survey.

\section{Materials}

A 7-point Likert type questionnaire consisting of 36 items was composed, ranging from 1 (totally disagree) to 7 (totally agree). We adjusted existing and validated scales in order to focus on research activities and the medical education setting. The scales, reliability, and sample items of the factors as measured by the questionnaire are shown in Tab. 1. Motivation for research was divided into questions regarding intrinsic and extrinsic motivation. Items for both types of motivation were based on Self-Determination questionnaires. Intrinsic motivation was based on the Interest/Enjoyment Scale [27, 39], and extrinsic motivation on the Value/Usefulness Scale [27, 39]. Self-efficacy was divided into questions regarding general, academic, and research self-efficacy. For measuring general self-efficacy, the Dutch General Self-Efficacy Scale was used [40]. For academic self-efficacy, the Academic Efficacy Scale from the Patterns of Adaptive Learning Scales (PALS) was used [41]. Items on the research self-efficacy scale were selfdeveloped and designed based on the previous two efficacy scales, but more specifically addressing self-efficacy regarding research. Perceptions of research were examined by using the subscale from the Student Perception of Research Integration Questionnaire (SPRIQ) focusing on students' beliefs about the value of research and learning [42]. Curiosity was measured with the Epistemic Curiosity Scale, divided in items on interest and deprivation curiosity [37]. Need for challenge was studied with self-developed items.

\section{Procedure}

The questionnaire was translated from English to Dutch, using the forward and backward translation procedure, and pretested on ten second-year medical students. Based on this pilot study, two items were clarified with minor adjustments in the use of words, and all first-year medical students were surveyed. Students were approached by the first author at the beginning of a workgroup session and asked to fill out the questionnaire. They were told that the

Table 1 Scales, reliability, and sample items of the questionnaire used in this study

\begin{tabular}{llll}
\hline Scale $^{\text {a }}$ & $N$ items & Cronbach's $\alpha$ & Sample item \\
\hline Intrinsic motivation & 5 & 0.79 & Doing research is fun \\
Extrinsic motivation & 4 & 0.77 & I think doing research improves my chances for my preferred residency spot \\
General self-efficacy & 3 & 0.78 & I trust my ability to solve problems \\
Academic self-efficacy & 3 & 0.84 & If I try I can deal with the most difficult parts of the course \\
Research self-efficacy & 3 & 0.88 & I feel I am competent enough to do research \\
Perceptions of research & 5 & 0.83 & It is important for medical professionals to have scientific skills \\
Interest curiosity & 5 & 0.80 & I enjoy investigating new ideas \\
Deprivation curiosity & 5 & 0.84 & If I am busy with a problem, I won't rest until I have the answer \\
Need for challenge & 3 & 0.81 & I desire an extra challenge on top of the curriculum
\end{tabular}

${ }^{\mathrm{a} A l l}$ items were answered on a 7-point Likert scale 
study was to investigate scientific education in the medical bachelor program, participation was voluntary, and all data would be processed anonymously. Students who agreed to participate received the questionnaire. This study was approved by the educational institutional review board of Leiden University Medical Center: IRB reference number OEC/OG/20161108/2.

\section{Analysis}

We used descriptive statistics to describe demographic variables and previous educational experiences of the students. To estimate the reliability of the scales in the questionnaire, we calculated Cronbach's alpha (Tab. 1). We calculated mean scores for every scale (range 1 to 7 ) and used independent t-tests, with Bonferroni correction, to study possible differences between male and female students. To test which factors influence motivation for research, we used univariate linear regressions, adjusted for gender and age. We applied a 95\% confidence interval. Based on existing literature we also constructed a cumulative model of explained variance $\left(R^{2}\right)$, starting with the most frequently investigated factors. We analyzed all data using IBM SPSS Statistics version 23 for Windows.

\section{Results}

Of all 316 students who were approached, 315 students agreed to participate in this study (99.7\%). The study included 90 male $(28.6 \%)$ and 225 female participants $(71.4 \%)$. Most of the students started medical education immediately after graduating from high school $(86.3 \%)$, resulting in a sample with a mean age of 18.57 years $(S D=1.37)$. Of these students, $30.2 \%$ indicated they had some kind of previous experience with participating in research.

Medical students were intrinsically $(M=5.49, S D=0.79)$ as well as extrinsically $(M=5.66, S D=0.80)$ motivated for research, as can be seen in Tab. 2 with the descriptives of the sample. Of all students, $30.1 \%$ scored a 6 or higher on intrinsic motivation and $42.5 \%$ scored a 6 or higher on extrinsic motivation for research. Analysis showed that female students scored slightly higher on both intrinsic and extrinsic motivation for research, but this was not statistically significant ( $p=0.14$ and $p=0.07$ respectively). The independent t-tests showed that male students scored significantly higher than female students on general self-efficacy ( $p<0.001$, male students scoring 0.39 higher), and academic self-efficacy $(p<0.001$, male students scoring 0.45 higher). These remained significant after Bonferroni correction ( 9 tests performed; $\alpha<0.05 / 9=0.0056)$. No significant

Table 2 Description of scores on factors measured in the questionnaire ${ }^{\mathrm{a}}$

\begin{tabular}{|c|c|c|c|c|c|c|}
\hline & $N$ & Mean & $\mathrm{SD}$ & Min & Max & $\geq 6(\%)$ \\
\hline Intrinsic motivation & 314 & 5.49 & 0.79 & 2.8 & 7.0 & 30.1 \\
\hline Extrinsic motivation & 315 & 5.66 & 0.80 & 3.0 & 7.0 & 42.5 \\
\hline General self-efficacy & 315 & 5.48 & 0.76 & 2.7 & 7.0 & 35.2 \\
\hline Academic self-efficacy & 315 & 5.43 & 0.93 & 2.3 & 7.0 & 36.4 \\
\hline Research self-efficacy & 314 & 4.85 & 0.97 & 2.0 & 7.0 & 18.1 \\
\hline Perceptions of research & 315 & 5.53 & 0.81 & 2.4 & 7.0 & 34.9 \\
\hline Interest curiosity & 315 & 5.46 & 0.77 & 3.2 & 7.0 & 28.1 \\
\hline Deprivation curiosity & 315 & 4.80 & 1.02 & 1.6 & 7.0 & 16.2 \\
\hline Need for challenge & 314 & 4.10 & 1.18 & 1.0 & 7.0 & 0.6 \\
\hline
\end{tabular}

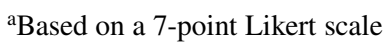

Table 3 Effects on intrinsic and extrinsic motivation: crude and adjusted for gender and age ${ }^{\mathrm{a}}$

\begin{tabular}{|c|c|c|c|c|}
\hline & \multicolumn{2}{|l|}{ Intrinsic motivation } & \multicolumn{2}{|l|}{ Extrinsic motivation } \\
\hline & $\begin{array}{l}\text { Crude } \\
\beta(95 \% \text { CI })\end{array}$ & $\begin{array}{l}\text { Adjusted } \\
\beta(95 \% \text { CI })\end{array}$ & $\begin{array}{l}\text { Crude } \\
\beta(95 \% \mathrm{CI})\end{array}$ & $\begin{array}{l}\text { Adjusted } \\
\beta(95 \% \mathrm{CI})\end{array}$ \\
\hline General self-efficacy & $0.257(0.154-0.360)$ & $0.298(0.192-0.404)$ & $0.169(0.053-0.285)$ & $0.213(0.095-0.331)$ \\
\hline Academic self-efficacy & $0.217(0.132-0.302)$ & $0.320(0.168-0.340)$ & $0.123(0.028-0.218)$ & $0.156(0.059-0.253)$ \\
\hline Research self-efficacy & $0.370(0.297-0.444)$ & $0.384(0.310-0.457)$ & $0.199(0.109-0.288)$ & $0.209(0.120-0.298)$ \\
\hline Perceptions of research & $0.430(0.339-0.520)$ & $0.438(0.350-0.527)$ & $0.330(0.226-0.433)$ & $0.338(0.235-0.441)$ \\
\hline Interest curiosity & $0.447(0.354-0.540)$ & $0.444(0.350-0.539)$ & $0.252(0.140-0.365)$ & $0.250(0.138-0.362)$ \\
\hline Deprivation curiosity & $0.256(0.182,0.331)$ & $0.245(0.169-0.320)$ & $0.187(0.102-0.271)$ & $0.182(0.097-0.267)$ \\
\hline Need for challenge & $0.310(0.250-0.370)$ & $0.316(0.257-0.376)$ & $0.189(0.117-0.262)$ & $0.191(0.119-0.264)$ \\
\hline
\end{tabular}

${ }^{a}$ All $p$-values were below 0.05 , all but three $p$-values were below 0.01 
Table 4 Cumulative model of explained variance of intrinsic and extrinsic motivation for research

\begin{tabular}{|c|c|c|c|c|c|c|c|c|c|}
\hline \multirow[b]{2}{*}{ Model } & \multirow[b]{2}{*}{ Variable } & \multicolumn{4}{|c|}{ Intrinsic motivation } & \multicolumn{3}{|c|}{ Extrinsic motivation } & \multirow[b]{2}{*}{ cum. $\mathrm{R}^{2}$} \\
\hline & & $\beta$ & $\mathrm{SE}$ & $p$ & cum. $\mathrm{R}^{2}$ & $\beta$ & SE & $p$ & \\
\hline 1 & Research self-efficacy & 0.495 & 0.037 & 0.000 & 0.245 & 0.239 & 0.045 & 0.000 & 0.057 \\
\hline \multirow[t]{2}{*}{2} & Research self-efficacy & 0.459 & 0.041 & 0.000 & 0.250 & 0.219 & 0.050 & 0.000 & 0.059 \\
\hline & Academic self-efficacy & 0.083 & 0.043 & 0.128 & & 0.045 & 0.053 & 0.461 & \\
\hline \multirow[t]{3}{*}{3} & Research self-efficacy & 0.464 & 0.044 & 0.000 & 0.251 & 0.208 & 0.053 & 0.001 & 0.060 \\
\hline & Academic self-efficacy & 0.094 & 0.052 & 0.153 & & 0.022 & 0.063 & 0.762 & \\
\hline & General self-efficacy & -0.020 & 0.066 & 0.770 & & 0.043 & 0.080 & 0.572 & \\
\hline \multirow[t]{4}{*}{4} & Research self-efficacy & 0.375 & 0.043 & 0.000 & 0.329 & 0.162 & 0.055 & 0.015 & 0.081 \\
\hline & Academic self-efficacy & 0.048 & 0.050 & 0.440 & & -0.001 & 0.063 & 0.984 & \\
\hline & General self-efficacy & -0.062 & 0.062 & 0.336 & & 0.021 & 0.080 & 0.782 & \\
\hline & Interest curiosity & 0.316 & 0.050 & 0.000 & & 0.164 & 0.064 & 0.008 & \\
\hline \multirow[t]{5}{*}{5} & Research self-efficacy & 0.372 & 0.043 & 0.000 & 0.329 & 0.144 & 0.055 & 0.033 & 0.088 \\
\hline & Academic self-efficacy & 0.050 & 0.050 & 0.426 & & 0.014 & 0.064 & 0.854 & \\
\hline & General self-efficacy & -0.064 & 0.063 & 0.328 & & 0.011 & 0.080 & 0.882 & \\
\hline & Interest curiosity & 0.307 & 0.061 & 0.000 & & 0.098 & 0.077 & 0.187 & \\
\hline & Deprivation curiosity & 0.015 & 0.044 & 0.802 & & 0.114 & 0.056 & 0.114 & \\
\hline \multirow[t]{6}{*}{6} & Research self-efficacy & 0.304 & 0.043 & 0.000 & 0.374 & 0.099 & 0.057 & 0.149 & 0.107 \\
\hline & Academic self-efficacy & -0.032 & 0.050 & 0.615 & & -0.040 & 0.066 & 0.600 & \\
\hline & General self-efficacy & -0.023 & 0.061 & 0.717 & & 0.038 & 0.080 & 0.620 & \\
\hline & Interest curiosity & 0.231 & 0.061 & 0.000 & & 0.049 & 0.079 & 0.523 & \\
\hline & Deprivation curiosity & -0.027 & 0.043 & 0.657 & & 0.086 & 0.056 & 0.231 & \\
\hline & Need for challenge & 0.277 & 0.037 & 0.000 & & 0.179 & 0.048 & 0.011 & \\
\hline \multirow[t]{7}{*}{7} & Research self-efficacy & 0.258 & 0.044 & 0.000 & 0.396 & 0.043 & 0.057 & 0.537 & 0.140 \\
\hline & Academic self-efficacy & -0.037 & 0.050 & 0.553 & & -0.046 & 0.064 & 0.537 & \\
\hline & General self-efficacy & -0.024 & 0.060 & 0.705 & & 0.037 & 0.078 & 0.621 & \\
\hline & Interest curiosity & 0.181 & 0.062 & 0.005 & & -0.012 & 0.080 & 0.873 & \\
\hline & Deprivation curiosity & -0.030 & 0.043 & 0.618 & & 0.083 & 0.055 & 0.242 & \\
\hline & Need for challenge & 0.243 & 0.037 & 0.000 & & 0.138 & 0.048 & 0.050 & \\
\hline & $\begin{array}{l}\text { Perceptions of re- } \\
\text { search }\end{array}$ & 0.184 & 0.050 & 0.001 & & 0.225 & 0.065 & 0.001 & \\
\hline
\end{tabular}

differences between male and female students were found on research self-efficacy $(p=0.33)$, perceptions of research $(p=0.50)$, interest curiosity $(p=0.61)$, deprivation curiosity $(p=0.35)$, and need for challenge $(p=0.55)$.

Univariate linear regression analysis indicated that all factors influenced intrinsic and extrinsic motivation for research significantly, as can be seen in Tab. 3. The associations remained significant after adjusting for gender and age. All regression coefficients were higher for intrinsic motivation as compared with extrinsic motivation for research.

The cumulative linear regression model indicated that self-efficacy explained $25.1 \%$ of the variance in intrinsic motivation for research. In this cumulative model, curiosity added $7.8 \%$ in explaining the variance, and if need for challenge and perceptions of research were included a total of $39.6 \%$ of the variance in intrinsic motivation for research can be explained, as illustrated in Tab. 4. With regard to extrinsic motivation for research, the total variance explained is $14 \%$, of which self-efficacy contributed $6 \%$ and the other factors all together explained $8 \%$.

\section{Discussion}

This study showed that first-year medical students are already motivated to do research, as they score relatively highly on both intrinsic and extrinsic motivation. Results also show that self-efficacy, perceptions of research, curiosity, and need for challenge are all positively associated with intrinsic and extrinsic motivation for research, also after adjusting for gender and age. The cumulative regression model indicated that around $40 \%$ of the variance in intrinsic motivation for research can be explained by the factors included in this study, especially research self-efficacy, interest curiosity, need for challenge, and perceptions of research were important. With regard to extrinsic moti- 
vation for research, only $14 \%$ of the variance was explained by the factors measured.

On a scale of 1-7 to indicate motivation for research, students scored on average above a 5, which implies that the group was both intrinsically and extrinsically motivated. This is an interesting finding, as one could assume that new medical students would be particularly interested in becoming a clinician. For instance, Rosenkranz and colleagues [3] showed that students in medical training acknowledged the relation between research and keeping up to date, but it was not until they experienced uncertainties in clinical practice that they understood the real relevance of research. A claim that the authors make is that medical students want to be clinicians, and that feelings of the importance of a good doctor conducting research appear in the clinical years of medical training [3]. Our results indicate that our students are already motivated and can see the importance of research at the beginning of their medical training.

Our findings are in line with previous studies in showing that self-efficacy contributes to motivation for research. It has been suggested that doctors with high research selfefficacy are more inclined to pursue a scientific career [34]. Our study suggests that this might also be the case for medical students, with higher research self-efficacy enhancing motivation of students for research this early in medical education. This is in line with Bandura's Social Cognitive Theory, which says that self-efficacy has a critical influence on motivation in general [32]. Our study provides support for the applicability of the Social Cognitive Theory in more specific settings, such as motivation for doing research.

Whereas all types of self-efficacy were positively related to both intrinsic and extrinsic motivation for research if tested separately, cumulative testing revealed that general and academic self-efficacy did not contribute to motivation on top of research self-efficacy. It has been argued that first-year medical students see research as a very specific task where very distinct skills are needed [43], which could mean that the items related to research self-efficacy are more concretely linked to research and thus motivation for research in this sample. Our results indicate that it is valuable to promote positive research self-efficacy beliefs in medical students. Ambiguity and uncertainty regarding an unknown activity may cause lower self-efficacy beliefs [32]. By providing students with more research related experiences early in the curriculum adapted to their level, students can become familiar with doing research. This is also in line with the Social Cognitive Theory, which states that mastery of an activity leads to higher self-efficacy beliefs [32]. With the right support, positive research self-efficacy beliefs can be stimulated, which can contribute to students' motivation for research.

In contrast to earlier studies [42-44], this study examined perceptions of research as the independent variable.
Our results showed that perceptions of research strongly influenced intrinsic and extrinsic motivation. One could argue that students may not be motivated to do research if it does not seem directly valuable for their development (i.e. intrinsic motivation) or future career (i.e. extrinsic motivation). This result could offer great opportunities because perceptions can be influenced $[42,43]$. By stimulating positive perceptions of research, motivation for research can be enhanced, thus it seems important to structure medical education in a way that positive perceptions are promoted. This could be done by exposing students to conducting research, and emphasizing its relevance for future clinical practice.

With regard to curiosity, the results in this study are in line with earlier findings showing that curiosity influences motivation for research $[22,24,25]$. It could be that curiosity reflects some kind of eagerness or ambition that underlies motivation, regardless of whether the nature of motivation is intrinsic or extrinsic. Our results indicate that interest curiosity, as well as deprivation curiosity, positively influence motivation for research. Both types of curiosity seemed to matter, but interest curiosity played a greater role in explaining differences in motivation for research. It is desirable to continue to stimulate students' curiosity.

Lastly, our findings showed that some medical students are in need of extra challenges and that this relates to their motivation for research. This indicates the importance of identifying students in need of extra challenges, in order to get them acquainted with the possibility to conduct research, thereby adding research to their options to meet with their need for challenge. In this way, identifying students in need of extra challenges may help to counter the physicianscientist shortage.

Milewicz and her colleagues showed that a MD-PhD program is a successful approach to train physician-scientists, and argued that this may be extended to postgraduate training as well [16]. Our results, however, suggest that these efforts could be pointed at much younger medical students too, by integrating research much earlier into medical training. Since first-year students are already motivated for research this early in medical training, it is our responsibility as educators to make sure that this motivation does not evaporate.

\section{Limitations and strengths}

A first limitation of this study is its cross-sectional design. It could be valuable to measure the factors at different time points to establish a deeper knowledge regarding how they relate to each other and to both types of motivation for research over time. Secondly, in our study we distinguish two types of motivation for research: intrinsic and extrinsic. SDT distinguishes these two types of motivation in the same way, but a refined version of this theoretical frame- 
work shows extrinsic motivation as a spectrum with four types of extrinsic motivation, varying in the quantity of external influences [26]. The items we used to compose the scale to measure extrinsic motivation are mostly related to the external and introjected regulation category. Future research would benefit from refining the concept of extrinsic motivation for research and investigating which factors influence what types of extrinsic motivation. Thirdly, motivation was self-reported and it is unclear whether students will act on their motivation by actually participating in research. Strengths of this study are the large sample size including almost all first-year medical students in our university medical centre and the high reliability of the scales (scales of 3-5 items, $\alpha>0.77$ ). This extent of participating students and the large sample size ensures that this study forms a sound base for investigating what influences motivation for research among first-year medical students.

\section{Conclusion}

Students' motivation for research could be enhanced by arranging the medical curriculum in a way that continuously stimulates positive self-efficacy beliefs, positive perceptions of research, and curiosity. Besides, we should be aware of and foster students' need for extra challenge by stimulating them to participate in research. Educators should emphasize the importance of conducting research for future clinical practice in such ways that students feel that it is valuable to fulfil their need for challenge by conducting research. Thus, this offers possibilities to catch them young and thereby contributes to the future physician-scientists workforce. The results of this study have shown that students are motivated for research early in medical training and therefore it is our duty to foster these students' motivation.

Acknowledgements The authors wish to thank John O'Sullivan, Kirsten Dijkhuizen, Renée Hendriks, and Marjolein Versteeg for their critical appraisal of the manuscript, and the second year students who participated in our pilot study.

Conflict of interest B.W.C. Ommering, F.M. van Blankenstein, C.J.F. Waaijer and F.W. Dekker declare that they have no competing interests.

Open Access This article is distributed under the terms of the Creative Commons Attribution 4.0 International License (http:// creativecommons.org/licenses/by/4.0/), which permits unrestricted use, distribution, and reproduction in any medium, provided you give appropriate credit to the original author(s) and the source, provide a link to the Creative Commons license, and indicate if changes were made.

\section{References}

1. Chang YJ, Ramnanan CJ. A review of literature on medical students and scholarly research: experiences, attitudes, and outcomes. Acad Med. 2015;90:1162-73.

2. van Eyk HJ, Hooiveld MHW, Van Leeuwen TN, et al. Scientific output of Dutch medical students. Med Teach. 2010;32:231-5.

3. Rosenkranz SK, Wang SY, Hu WD. Motivating medical students to do research: a mixed methods study using self-determination theory. BMC Med Educ. 2015; https://doi.org/10.1186/s12909-0150379-1.

4. Moraes DW, Jotz M, Menegazzo WR, et al. Interest in research among medical students: challenges for the undergraduate education. Rev Assoc Med Bras. 2016;62:652-8.

5. Dekker FW. Science education in medical curriculum: teaching science or training scientists? Med Sci Educ. 2011;21:258-60.

6. de Beaufort AJ, de Goeij AFPM. Academic and scientific education in medical curricula in the Netherlands: a programme director's view. Perspect Med Educ. 2013;2:225-9.

7. Dekker FW. Achieving research competences through medical education. Perspect Med Educ. 2013;2:178-80.

8. Kosik RO, Tran DT, Fan APC, et al. Physician scientist training in the United States: a survey of the current literature. Eval Health Prof. 2016;39:3-20.

9. Solomon SS, Tom SC, Pichert J, Wasserman D, Powers AC. Impact of medical student research in the development of physicianscientists. J Investig Med. 2003;51:149-56.

10. Harding CV, Akabas MH, Andersen OS. History and outcomes of 50 years of physician-scientist training in medical scientist training programs. Acad Med. 2017;92:1390-8.

11. Weaver AN, McCaw TR, Fifolt M, Hites L, Lorenz RG. Impact of elective versus required medical school research experiences on career outcomes. J Investig Med. 2017;65:942-8.

12. Ommering BWC, Dekker FW. Medical students' intrinsic versus extrinsic motivation to engage in research as preparation for residency. Perspect Med Educ. 2017; https://doi.org/10.1007/s40037017-0388-3.

13. Goldhamer MEJ, Cohen AP, Bates DW, et al. Protecting an endangered species: training physicians to conduct clinical research. Acad Med. 2009;84:439-45.

14. Reinders JJ, Kropmans TJ, Cohen-Schotanus J. Extracurricular research experience of medical students and their scientific output after graduation. Med Educ. 2005;39:237.

15. Hall AK, Mills SL, Lund PK. Clinician-investigator training and the need to pilot new approaches to recruiting and retaining this workforce. Acad Med. 2017;92:1382.

16. Milewicz DM, Lorenz RG, Dermody TS, Brass LF. National Association of MDPPEC. Rescuing the physician-scientist workforce: the time for action is now. J Clin Invest. 2015;125:3742-7.

17. Green EP, Borkan JM, Pross SH, et al. Encouraging scholarship: medical school programs to promote student inquiry beyond the traditional medical curriculum. Acad Med. 2010;85:409-18.

18. Morel PA, Ross G. The physician scientist: balancing clinical and research duties. Nat Immunol. 2014;15:1092-4.

19. Siemens DR, Punnen S, Wong J, Kanji N. A survey on the attitudes towards research in medical school. BMC Med Educ. 2010; https:// doi.org/10.1186/1472-6920-10-4.

20. Varki A, Rosenberg LE. Emerging opportunities and career paths for the young physician-scientist. Nat Med. 2002;8:437-9.

21. Nel D, Burman RJ, Hoffman R, Randera-Rees S. The attitudes of medical students to research. S Afr Med J. 2014;104:32-6.

22. Abu-Zaid A, Alkattan K. Integration of scientific research training into undergraduate medical education: a reminder call. Med Educ Online. 2013;18:22832. 
23. Furtak EM, Seidel T, Iverson H, Briggs DC. Experimental and quasi-experimental studies of inquiry-based science teaching: a meta-analysis. Rev Educ Res. 2012;82:300-29.

24. Graham MJ, Frederick J, Byars-Winston A, Hunter AB, Handelsman J. Increasing persistence of college students in STEM. Science. 2013;341:1455-6.

25. de Jong PGM, Haramati A. Teaching to develop scientific engagement in medical students. In: Huggett KN, Jeffries WB, editors. An introduction to medical teaching. Dordrecht: Springer; 2014.

26. Ten Cate TJ, Kusurkar RA, Williams GC. How self-determination theory can assist our understanding of the teaching and learning processes in medical education. AMEE guide No. 59. Med Teach. 2011;33:961-73.

27. Ryan RM, Deci EL. Self-determination theory and the facilitation of intrinsic motivation, social development, and well-being. Am Psychol. 2000;55:68-78.

28. Mina S, Mostafa S, Albarqawi HT, et al. Perceived influential factors toward participation in undergraduate research activities among medical students at Alfaisal University-College of Medicine: a Saudi Arabian perspective. Med Teach. 2016;38:S31-S6.

29. Abu-Zaid A. Research skills: the neglected competency in tomorrow's 21st-century doctors. Perspect Med Educ. 2014;3:63-5.

30. Green M, Jones P, Thomas JX Jr. Selection criteria for residency: results of a national program directors survey. Acad Med. 2009;84:362-7.

31. Vansteenkiste M, Sierens E, Soenens B, Luyckx K, Lens W. Motivational profiles from a self-determination perspective: the quality of motivation matters. J Educ Psychol. 2009;101:671-88.

32. Bandura A. Self-efficacy. The exercise of control. New York: Freeman; 1997.

33. Robnett RD, Chemers MM, Zurbriggen EL. Longitudinal associations among undergraduates' research experience, self-efficacy, and identity. J Res Sci Teach. 2015;52(6):847-67.

34. Bierer SB, Prayson RA, Dannefer EF. Association of research self-efficacy with medical student career interests, specialization, and scholarship: a case study. Adv Health Sci Educ Theory Pract. 2015;20:339-54.

35. Ferla J, Valcke M, Schuyten G. Judgments of self-perceived academic competence and their differential impact on students' achievement motivation, learning approach, and academic performance. Eur J Psychol Educ. 2010;25:519-36.

36. Berlyne DE. A theory of human curiosity. Br J Psychol. 1954;45: 180-91.

37. Litman JA. Interest and deprivation factors of epistemic curiosity. Pers Individ Dif. 2008;44:1585-95.
38. van der Rijst R, Wolfensberger M. Docentopvattingen over de meerwaarde van honoursonderwijs voor het leren van talentvolle en gemotiveerde studenten. Tijdschri Hoger Onderwijs. 2014; 31/32(4/1):52-65.

39. Deci EL, Eghrari H, Patrick BC, Leone DR. Facilitating internalization: the self-determination theory perspective. J Pers. 1994;62:119-42.

40. Schwarzer R, Jerusalem M. Generalized self-efficacy scale. In: Weinman J, Wright S, Johnston M, editors. Measures in health psychology: A user's portfolio. Causal and control beliefs. Windsor: NFER-NELSON; 1995. pp. 35-7.

41. Midgley C, Maehr ML, Hruda LZ, Anderman E, Anderman L, Freeman KE. Manual for the Patterns of Adaptive Learning Scales (PALS). Ann Arbor: University of Michigan; 2000.

42. Vereijken MWC, van der Rijst RM, de Beaufort AJ, van Driel JH, Dekker FW. Fostering first-year student learning through research integration into teaching: Student perceptions, beliefs about the value of research and student achievement. Innov Educ Teach Int. 2016; https://doi.org/10.1080/14703297.2016.1260490.

43. Imafuku R, Saiki T, Kawakami C, Suzuki Y. How do students' perceptions of research and approaches to learning change in undergraduate research? Int J Med Educ. 2015;6:47-55.

44. Ribeiro L, Severo M, Pereira M, Ferreira MA. Scientific skills as core competences in medical education: What do medical students think? Int J Sci Educ. 2015;37:1875-85.

Belinda W.C. Ommering MSc, is a PhD candidate in Medical Education, Center for Innovation in Medical Education, Leiden University Medical Center, the Netherlands.

Floris M. van Blankenstein $\mathrm{PhD}$, is a senior researcher in Medical Education, Center for Innovation in Medical Education, Leiden University Medical Center, and an educational consultant at Leiden University Graduate School of Teaching, the Netherlands.

Cathelijn J.F. Waaijer $\mathrm{PhD}$, is a postdoctoral researcher in Medical Education, Center for Innovation in Medical Education, Leiden University Medical Center, the Netherlands.

Friedo W. Dekker $\mathrm{PhD}$, is a full professor in Undergraduate Research in Medical Education, Department of Clinical Epidemiology and Center for Innovation in Medical Education, Leiden University Medical Center, the Netherlands. 